\title{
Size-dependent functional response of Xenopus laevis feeding on mosquito larvae
}

\author{
Corey J Thorp ${ }^{1}$ ， Mhairi E Alexander ${ }^{1,2}$ ， James R Vonesh ${ }^{1,3}$ ， John Measey ${ }^{\text {Corresp. } 1}$ \\ ${ }^{1}$ Centre for Invasion Biology, Department of Botany \& Zoology, Stellenbosch University, Stellenbosch, South Africa \\ 2 Institute for Biomedical and Environmental Health Research (IBEHR), School of Science and Sport, University of the West of Scotland, Paisley, UK \\ 3 Department of Biology, Virginia Commonwealth University, Richmond, Virginia, USA \\ Corresponding Author: John Measey \\ Email address: john@measey.com
}

Predators can play an important role in regulating prey abundance and diversity, determining food web structure and function, and contributing to important ecosystem services, including the regulation of agricultural pests and disease vectors. Thus, the ability to predict predator impact on prey is an important goal in ecology. Often, predators of the same species are assumed to be functionally equivalent, despite considerable individual variation in predator traits known to be important for shaping predator-prey interactions, like body size. This assumption may greatly oversimplify our understanding of within-species functional diversity and undermine our ability to predict predator effects on prey. Here, we examine the degree to which predator-prey interactions are functionally homogenous across a natural range of predator body sizes. Specifically, we quantify the size-dependence of the functional response of African clawed frogs (Xenopus laevis) preying on mosquito larvae (Culex pipiens). Three size classes of predators, small (15 - 30 $\mathrm{mm}$ snout-vent length), medium (50 - $60 \mathrm{~mm}$ ) and large (105-120 mm), were presented with five densities of prey to determine functional response type and to estimate search efficiency and handling time parameters generated from the models. The results of mesocosm experiments showed that type of functional response of $X$. laevis changed with size: small predators exhibited a Type II response, while medium and large predators exhibited Type III responses. Functional response data showed an inversely proportional relationship between predator attack rate and predator size. Small and medium predators had highest and lowest handling time, respectively. The change in functional response with the size of predator suggests that predators with overlapping cohorts may have a dynamic impact on prey populations. Therefore, predicting the functional response of a single size-matched predator in an experiment may misrepresent the predator's potential impact on a prey population. 
1 Size-dependent functional response of Xenopus laevis feeding on mosquito larvae

2

3 C. J. Thorp ${ }^{1}$, M. E. Alexander ${ }^{1,2}$, J. R. Vonesh ${ }^{1,3}$, J. Measey*1

4

$5{ }^{1}$ Centre for Invasion Biology, Department of Botany \& Zoology, Stellenbosch University, South Africa

$6{ }^{2}$ Institute for Biomedical and Environmental Health Research (IBEHR), School of Science and Sport,

7 University of the West of Scotland, Paisley PA1 2BE, Scotland, UK

$8{ }^{3}$ Department of Biology, Virginia Commonwealth University, Richmond, Virginia, 23235, USA

9

$10 *$ Corresponding Author: John Measey

11 Email: john@measey.com

12 Telephone: +27218082385

13 Address: Centre for Invasion Biology, Department of Botany \& Zoology, Stellenbosch University, South

14 Africa

15

16

17 Corey James Thorp, orcid.org/0000-0003-1580-0775

18 Mhairi Alexander, orcid.org/0000-0002-8348-7461

19 James Vonesh, orcid.org/0000-0003-2481-9988

20 John Measey, orcid.org/0000-0001-9939-7615

21

22 


\section{Abstract}

25 Predators can play an important role in regulating prey abundance and diversity, determining food web 26 structure and function, and contributing to important ecosystem services, including the regulation of 27 agricultural pests and disease vectors. Thus, the ability to predict predator impact on prey is an important 28 goal in ecology. Often, predators of the same species are assumed to be functionally equivalent, despite 29 considerable individual variation in predator traits known to be important for shaping predator-prey 30 interactions, like body size. This assumption may greatly oversimplify our understanding of within31 species functional diversity and undermine our ability to predict predator effects on prey. Here, we 32 examine the degree to which predator-prey interactions are functionally homogenous across a natural 33 range of predator body sizes. Specifically, we quantify the size-dependence of the functional response of 34 African clawed frogs (Xenopus laevis) preying on mosquito larvae (Culex pipiens). Three size classes of predators, small (15-30 $\mathrm{mm}$ snout-vent length), medium $(50-60 \mathrm{~mm})$ and large $(105-120 \mathrm{~mm})$, were presented with five densities of prey to determine functional response type and to estimate search efficiency and handling time parameters generated from the models. The results of mesocosm experiments showed that type of functional response of $X$. laevis changed with size: small predators exhibited a Type II response, while medium and large predators exhibited Type III responses. Functional response data showed an inversely proportional relationship between predator attack rate and predator size. Small and medium predators had highest and lowest handling time, respectively. The change in functional response with the size of predator suggests that predators with overlapping cohorts may have a dynamic impact on prey populations. Therefore, predicting the functional response of a single size- 
50

51

52

53

54

55

56

57

58

59

60

61

62

63

64

65

66

67

68

69

70

71

72

73

74

\section{Introduction}

Predator-prey interactions are important in regulating prey populations and determining the structure of aquatic communities (Brooks and Dodson, 1965; Carpenter et al. 1985). Predators directly impact prey populations by causing a decline in survival and recruitment, whereas prey quantity and quality directly affect feeding rate, growth, density, reproductive success and population dynamics of predators (Miller $e t$ al. 1988; Leucke et al. 1990; Beauchamp et al. 2007). Consequently, these interactions can affect the distribution, habitat choice, behaviour and foraging strategies of both predators and prey (Eggers, 1978; Sih, 1982; Walls et al. 1990). Classical predator-prey models typically assume that individual predators within a population are functionally equivalent (Lotka, 1924; Volterra, 1931; Rosenzweig and MacArthur, 1963). However, most species undergo considerable change in size during their ontogeny. Changing scaling relationships between predators and prey are known to produce nonlinear interactions, with intermediate size predators imposing the strongest per capita top-down interactions (Vucic-Pestic et al. 2010). Size differences of prey may have significant consequences for predator-prey interactions (Jansson et al. 2007, Rudolf 2008, McCoy et al 2011). The few studies that have quantified how predator size influences shapes of functional responses on the same prey have highlighted size-dependence of predator handling time and attack rate (e.g. Eveleigh and Chant 1981, Vucic-Pestic et al. 2010, Milonas et al., 2011, Anderson et al., 2016), and even the general form of the functional response (Anderson et al., 2016). These studies show that assuming that predators of the same species are functionally equivalent may greatly oversimplify our understanding of within-species functional diversity and undermine our ability to predict predator effects on prey.

70 The f ${ }^{\text {ional response is }}$ key relationship linking predator and prey dynamics and describes the 1 relationship between a predators uptake of prey as a function of the prey density. Holling (1963) described the three most common models of predator functional response. A Type I response is characterized as having a constant attack rate $a$ with no handling time $h$ (Holling, 1959; Hassell, 1978). A Type II response includes handling time and as a result, the rate of prey consumption by a predator 
75 divided by prey abundance declines with prey abundance, but instead declines with higher prey densities

76 due to handling constraints. Handling time is the period predators are occupied with processing (e.g.,

77 ingesting, digesting) captured prey and are not able to engage new prey items. This constraint can produce

78 nonlinearity to the relationship between prey availability and prey eaten. Predators that exhibit a Type II

79 response typically de-stabilise prey populations is due to the positive feedback on prey population growth

80 caused by decreased predator consumption rates as a prey population increases, as predators are unable to

81 regulate prey populations at densities beyond predator satiation (Rosenzweig and MacArthur, 1963;

82 Oaten and Murdoch, 1975). A Type III response is defined by an accelerating increase in prey capture

83 with increasing prey density for a range of low prey densities. The proportion of prey consumed initially

84 increases with increasing prey availability then declines as in a Type II response (Holling, 1959; Hassell,

85 1978). This can create a refuge for prey at low densities, facilitating the persistence of prey populations,

86 and a physical refuge in limited supply can create a Type III response. Therefore, the type of functional

87 response a predator exhibits can result in quite different outcomes for prey. By describing the response,

88 the potential impact at a population level may be elucidated (e.g., Rosenzweig and MacArthur, 1963).

89

90 Several factors may influence the type of functional response exhibited for a specific predator-prey

91 interaction. This includes environmental conditions (e.g. Laverty et al. 2015, Englund et al. 2011) as well

92 as body size of participants (e.g. Brose et al. 2005, McCoy et al. 2011, Tucker et al. 2014, Anderson et

93 al., 2016). Size variation is a common feature in animal populations and influences predator-prey

94 interactions, competition and individual life histories (Ebenman, 1988; Wilbur 1988; Samhouri et al.

95 2009; Asquith and Vonesh, 2012). However, preferred prey typically change with ontogeny for many

96 predators such that experiments are not able to present common prey across a range of predator sizes. For

97 example, Milonas et al. (2011) investigated the functional response of different instars of larval ladybirds

98 (Nephus includens) using increasing prey sizes; all exhibited the same functional response type (Type II),

99 but showed small differences in handling time and attack rate. For iteroparous amphibians with

100 indeterminate growth and overlapping cohorts, individual body size is especially important (Márquez et 
101 al. 1997; Werner, 1994). Smaller predators in these populations may be limited by the range of prey size

102 they can consume (e.g., handling time may be greater for smaller predators; Anderson et al., 2016) and 103 are often more efficient at assimilating consumed prey due to their high metabolic rates (Werner, 1994;

104 Asquith and Vonesh, 2012). In contrast, their larger conspecifics are generally less efficient in converting

105 prey biomass into predator biomass but may have a much broader range of prey sizes that they can

106 consume (Schoener, 1969; Asquith and Vonesh, 2012; Cohen et al. 1993). In these populations, smaller

107 predators may then have to deal with competition from larger predators that may result in a recruitment

108 bottleneck that could potentially extend the period of time smaller predators remain at a vulnerable size

109 (Schroder et al. 2009; Asquith and Vonesh, 2012). Therefore, understanding the relationship between

110 consumer size and their feeding rates can provide insights into intra-cohort interactions and population

111 dynamics of structured predator populations.

112

113 To investigate the role of predator size on functional response, we conducted a comparative functional

114 response study between African clawed frogs, Xenopus laevis, of different sizes on a single prey type

115 mosquito larvae, Culex pipiens, in order to answer the following questions: 1) Do differences exist in

116 functional response type between different sized predators of the same species for a standardised prey

117 size? 2) Are there differences in the functional response parameters (attack rate, handling time, and

118 maximum feeding rate) of different sized predators?

120 Materials and methods

121 Study species

122 The focal predator species, the African clawed frog (Xenopus laevis, Daudin), has a wide distribution in 123 southern Africa and inhabits permanent and temporary water bodies across its native range (Measey 124 2004). In X. laevis, individuals within a population can vary as much as 8-fold in body size, with 125 metamorphs as small as $15 \mathrm{~mm}$ snout vent length (SVL), to large adults exceeding $120 \mathrm{~mm} \mathrm{SVL}$ (de 
126 Villiers et al. 2016). Xenopus laevis is a voracious predator with a broad diet that includes a wide variety

127 of prey sizes and species, ranging from vertebrates, such as adult frogs, to very small prey, such as

128 zooplankton (Vogt et al. 2017; Courant et al. 2017).

129

130 Culex pipiens (Bedford), the northern house mosquito, is among the most widely distributed species of 131 mosquito in the world (Barr 1967). It is an important vector of St. Louis Encephalitis, West Nile Virus,

132 Western Equine Encephalitis, Heartworm in dogs, and bird Malaria (Turell 2012). Culex pipiens breed in

133 temporary surface-water habitats such as swamps, marshes, bogs, rice fields, and pastures, which can lack

134 fish predators. Thus, Xenopus laevis, which also utilize these temporary surface-water habitats and can

135 readily disperse overland (Measey 2016; de Villiers \& Measey 2017) to colonize newly formed aquatic

136 habitats preferred by mosquitoes, may play a role in mitigating environmental health risk posed by this 137 species.

138

139 Specimen collection and maintenance

140 Adult $X$. laevis were captured in the field using funnel traps baited with chicken liver at the Jonkershoek

141 fish hatchery $\left(-33.9631^{\circ} \mathrm{S} ; 18.9252^{\circ} \mathrm{E}\right)$, Western Cape Province, South Africa. All captured Xenopus

142 were marked with a Passive Integrated Transponder (PIT) tag. Culex pipiens were collected from

143 naturally colonised populations using 501 experimental tubs containing water and hay. Predators

144 collected from Jonkershoek were transported to the Welgevallen Experimental Farm $\left(-33.9426^{\circ} \mathrm{S}\right.$;

$14518.8664^{\circ} \mathrm{E}$ ) where they were kept for a maximum of two weeks in \pm 5001 holding tanks. Predators were

146 maintained on a diet of chicken livers ad libitum. All applicable institutional and/or national guidelines

147 for the care and use of animals were followed, with ethics clearance for experiments granted by

148 Stellenbosch University Research Ethics Committee: Animal Care \& Use (SU-ACUD15-00011).

149 Collection permits were granted by CapeNature (permit number AAA007-00159-0056).

150

151 Experimental procedure 
152 To quantify the functional response of Xenopus laevis preying upon Culex pipiens mosquitoes dependent

153 on consumer body size, we conducted a 3 x 5 factorial experiment in which three size classes of predator

154 were crossed with five prey densities in independent trials. Predators were classified into three size

155 classes according to their snout vent length (SVL, mm; mean \pm SD): small (21.0 \pm 3.9$)$, medium (54.6 \pm

156 2.6) and large (113.3 \pm 4.6$)$. Culex pipiens larvae used were size-sorted ( 7 - $9 \mathrm{~mm}$ thorax length) using

157 mesh screening and were all likely fourth instar. Prey density treatments were 20, 50, 100, 200 and 500

158 larvae per \pm 5001 rectangular mesocosm, giving densities of $0.04,0.1,0.2,0.4$ and 1 mosquitoes per litre,

159 respectively. Treatments with single predators were randomly assigned and replicated four times.

160

161 Experiments were conducted between 15-Mar and 13-May-2016 in individual \pm 5001 rectangular

162 mesocosms placed outdoors in single block at the Welgevallen Experimental Farm, Stellenbosch.

163 Mesocosmere rectangular plastic bins with a capacity of 1000 1, half-filled with water to $50 \mathrm{~cm}$ depth

164 (volume of \pm 5001 ), and covered with mesh screening to prevent any disturbance. These frogs are active

165 between evening and midnight of each day (Ringeis et al 2017), while the mosquito larvae are suspended

166 at the surface at all times. Predators were placed into the mesocosms $24 \mathrm{~h}$ prior to experimental trials to

167 acclimate. Hunger levels were standardised by not feeding Xenopus for $48 \mathrm{~h}$ prior to the experiment.

168 Experiments were initiated at 18:00 with the addition of mosquito larvae and were completed once the

169 predators were removed after $14 \mathrm{~h}$ at 08:00 the following day. Remaining prey were counted in order to

170 determine the predator's functional response. During the experiment, we maintained a mesocosm with the

171 highest density of prey, but without predators, to assess short-term background mortality or biases in

172 recovery. We observed no mortality and recaptured all larvae from these controls. Thus, we assume

173 background mortality from causes other than Xenopus predation in experimental trials was negligible.

\section{Statistical analysis}


177 All functional responses were modelled in R v3.3.1 (R Core Team, 2013) using the "friar" package 178 (Pritchard, 2014) via a two-step process.

179

180 First, we used logistic regressions to distinguish between Type III and I \& II functional response types

181 (Trexler et al. 1998, Juliano, 2001). To accomplish this, we modelled proportion of prey killed as a

182 function of prey density. If the first-order term of the analysis was significantly negative, the functional 183 response was considered a Type II. If the first-order term was significantly positive, followed by a 184 significantly negative second-order term, the functional response was considered a Type III (Juliano, 185 2001).

186

187 Second, once we determined the general form, functional responses were fit using a flexible model that 188 includes a scaling exponent $q$ to allow for a continuum of shapes between types I, II and III to be 189 described (Barrios-O’Neill et al. 2015; Real, 1977):

190

191

$N_{e}=N_{0}\left(1-\exp \left(b N_{0}^{q}\left(h N_{e}-T\right)\right)\right)$

Eq. 1

192

193

where $N_{e}$ is the number of prey eaten, $N_{0}$ is the initial prey density, $b$ is the attack rate, $h$ is the handling

194 time, $q$ is the scaling exponent and $T$ is the total time available. Where Type II responses occur, $q=0$, and 195 functional responses become increasingly Type III in form when $q>0$. In order to compare functional responses of different size classes, $95 \%$ confidence intervals were fitted around functional response curves by non-parametrically bootstrapping the datasets $(n=2000)$.

198

199

200 Results

201 Functional response model 
202 Logistic regression indicated that of the three size classes of $X$. laevis, small frogs clearly exhibited a 203 Type II functional response, as revealed by the significantly negative first-order term (Table 1, Fig. 1). 204 The scaling exponent, $q$, was therefore fixed at 0. Logistic regression indicated Type III responses for 205 medium and large size classes (Table 1, Fig. 1). For these size classes, $q$ was unfixed for initial model 206 fitting and then fixed at the generated maximum likelihood estimate. Bootstrapping was performed on the 207 parameters $b$ and $h$ to provide an error estimate.

208

209 Table 2 provides estimates for the functional response parameters $b$ and $h$ for all size classes studied and $q$ 210 in the case of medium and large $X$. laevis. The only differentiation occurring between functional response 211 curves was at low prey densities (i.e. 0-100) where small frogs had higher predation rates compared to 212 medium and large size classes (Fig. 1). This was supported by the higher attack rate for small size classes 213 (Fig. 2a). Responses converged at higher densities between medium and large size classes as well as small 214 and large size classes, with overlapping confidence intervals for the asymptotes (Fig. 1). and handling 215 time coefficients (Fig. 2b) overlapping. Handling time coefficient was highest in the smallest predator 216 size class, and lowest in the medium size class, with a significant difference (Table 2; Fig. 2b). Handling 217 time for frogs in the largest size class was intermediate, and not significantly different between medium 218 and small frogs (Fig. 2b).

219

220

221

\section{Discussion}

223 We found changes in the basic form of the functional response type between different sized predators of 224 the same species for a standardised prey size. The smallest predator size class exhibited a Type II 225 response compared to Type III responses as exhibited in medium and large adults. This finding has 226 important implications for understanding how predator-prey dynamics change in systems where predators 227 undergo large changes in body size relative to their prey through ontogeny. Moreover, we show predator 
228

229

230

231

232

233

234 235 236

237

238

239

240

241

242

243

244

245

246

247

248

249

250

251

252 253

attack rates and handling times change with predator size. Search efficiency was found to be inversely proportional to predator body size whereas handling time exhibited a U-shaped function and maximum feeding rate was observed in medium sizes of $X$. laevis. Predators of the same species are often assumed to be functionally equivalent, despite individual variation in predator traits known to be important for shaping predator-prey interactions, like body size (McCoy et al 2011, but see Gonzalez-Suarez et al. 2011). This assumption may greatly oversimplify our understanding of within species functional diversity and undermine our ability to predict predator effects on prey. Here we examine the degree to which predator-prey interactions are functionally homogenous across a natural range of predator body size.

Frequently, handling time initially decreases with increasing predator size, which can be attributed to an increased digestive capacity and gape size (Mittelbach, 1981; Persson, 1987). However, Persson et al. (1998) theorised that handling time will decrease until it reaches a minimum value, as found by Mittelbach (1981), and at some point will begin to increase with predator size (e.g., Persson,1987). This is consistent with our findings where medium sized predators were found to have the lowest handling time, potentially representing the minimum amount of handling time across all size classes. A possible explanation is that large predators will have difficulty in handling very small prey and small predators may have an increased handling time due to their digestive capacity or the prey being large to ingest by inertial suction (Persson, 1987). Therefore, it might be expected that these larger predators will favour larger prey in order to increase their capture success rate. However, there are multiple examples in the literature that show $X$. laevis predators, independent of size, predominantly consume zoobenthos and zooplankton (Courant et al. 2017). This could be attributed to prey availability and density where the lower limit for prey size consumption depends on prey encounter rate and the cost of consumption (Elton, 1927; Owen-Smith and Mills, 2008). Very little movement is required to feed on both zooplankton and zoobenthos which would reduce energy cost and predation risk. Low densities of small prey offer very little reward to large predators which may explain why both medium and large sized predators did not consume high proportions of prey when prey density was low (Griffiths, 1980). 
255 There are a number of examples that exist showing unimodal ('dome shaped') relationships between 256 attack rate and predator size (Aljetlawi et al. 2004; Tripet and Perrin, 1994; Werner, 1988). In aquatic 257 predators, the initial increase of attack rate with predator size is most likely due to an increase in predator 258 search speed, which will positively affect prey encounter rates (Keast \& Webb 1966; Schoener, 1969).

259 The eventual decline in attack rate with increasing predator size could be due to either prey being 260 relatively too small to be detected or the inability of a predator to make fine-tuned movements, resulting 261 in lower prey capture success rate (Hyatt, 1979). However, in our study, attack rate was not dome shaped 262 with respect to prey size and instead negatively correlated with size class (Table 1). One explanation is 263 that the dome shape may only be observed if the experiment had additional intermediate predator size

264 265 266 267 268 269

270 271 272 273 274 275 276 277 278 279

classes. Therefore, attack rate may yet hold a dome shaped function of predator size, which may exist between the small and medium size classes measured in this study. Another explanation for the negative correlation could be that the prey are already at the optimal size for maximum attack rate in small sized predators. There is also a possibility that the relative fitness gain from small prey items is too small to make it worthwhile for larger foragers to be active.

Milonas et al. (2011) found different feeding modes in a predatory ladybird (Nephus includens) in which smaller instars (2nd instar, $2 \mathrm{~mm}$ ) were found to partially consume prey of different sizes, whereas larger instars (4th instar, $3.3 \mathrm{~mm}$ ) consumed prey whole. The differences in feeding mode between the large and small predators led to differences in handling time when prey size was increased. Smaller predators were able to maintain a constant handling time, whereas larger predator's handling time increased with prey size. However, in our study all predators completely consumed prey; thus the mosquito larvae were not too large for the smallest frogs to consume. The lower capture success rate found in medium and large predators was most likely due to their limited ability to hold relatively small prey (CJT pers. obs.), similar to observations made on fish (Persson, 1987). Observation data also showed a response from predators to movement from prey. Regardless of the predator's positioning in relation to the prey, detection was most 
280 likely when prey exhibited sudden movements. Xenopus laevis do not principally use visual or olfactory 281 cues in order to detect aquatic prey, and instead rely on their sensitive lateral line systems (see Elepfandt, 282 1996).

283

284 Despite the potentially profound implications for predator-prey dynamics, few studies directly test 285 whether the basic form of the functional response changes with consumer size. Recently, Anderson et al., 286 (2016) found that the form of the functional response changed with predator size (hatchling to larval 287 ambystomatid salamanders), with smaller predators (adult ambystomatid salamanders) being more limited 288 by handling times than large predators. In other words, smaller predators tended to exhibit a Type II functional response while larger predators exhibited a Type I functional response for the same prey. Type

290

291

292

293

294

295

296

297 298 299 300 301 302 303 304 305

II functional responses as defined by Eq 1, collapse to a Type I functional response when estimates of the handling time parameter overlap zero. None of the predators exhibited a Type III functional response. In this study, we find that both medium and large sized X. laevis showing a Type III response and small predators exhibiting a Type II, smaller predators may be able to exploit prey at low densities. There is a trend towards higher $q$ values (or scaling exponent) and a more stabilising response (Alexander et al. 2012).

Thus, the medium size class of $X$. laevis is most likely to destabilise predator-prey dynamics given fast handling times and a reduction in consumption at low densities as indicated by a lower $q$ than the large size class. Small frogs are likely to destabilise prey at low densities, but overall they have a much lower handling time, and therefore a higher feeding rate. When prey density is low, there is an increase in predation from small predators, and when prey density is high, there would be an increase in predation from larger predators (Rindone and Eggleston, 2011). Densities of X. laevis are known to reach very high levels, especially in invasive populations (e.g. Measey 2001; Lobos and Measey 2002; Faraone et al 2008), but also in natural assemblages (de Villiers et al. 2016). The present study also has a conservation context as the smaller, but functionally similar, congener $X$. gilli is threatened by competition from $X$. 
306 laevis (see Vogt et al. 2017). Thus, having a population of predators of different sizes at the same time

307 means that there is little relief for multiple prey species, and could lead to prey extirpation (Hassell,

308 1978). This could be advantageous, if the prey species is a potential disease vector, as in the case of Culex

309 pipiens. Prey may experience a similar scenario with fish in aquatic ecosystems due to many fish species

310 consisting of populations with overlapping cohorts (Werner, 1984). However, in populations where

311 differences in predator size are less pronounced, prey may experience only one type of predator response

312 (Milonas et al. 2011).

313

\section{Conclusion}

315 Studies often compare functional responses of native and invasive predators and important inferences are

316 made about the potential impacts of these invaders (reviewed by Dick et al. 2013). However, little

317 research focuses on the potential role predator size could play in determining these functional responses.

318 Predators can change their foraging preference as they age and grow and selecting a single size class in

319 functional response experiments to represent an entire population may not be the best representation of populations with overlapping cohorts and large size ranges. It is important to consider whether the same

321

322

323

324

325

326

327

328

329

330 pattern would be seen on different prey species. How would functional response curves be affected if prey size was increased (e.g., see McCoy et al. 2011)? There may be a shift from a Type III to a Type II functional response in our medium and large sized predators as prey size increases. Similarly, it could be asked how prey traits (e.g. activity, shape, colour, etc.) affect functional response curves when size is kept constant. It is therefore important to answer these questions so that a predator population's functional response is correctly represented. This study has shown parameters such as attack rate, handling time and maximum feeding rate as well as functional response type are dependent on predator body size.

Therefore, when conducting a functional response experiment it is vital to consider both predator and prey size, foraging strategy and prey species.

331 


\section{Acknowledgements}

333 We would like to thank members of the MeaseyLab for their help in preparation and harvesting of

334 experiments: Erin Jooste, Ana Nunes, Giovanni Vimercati, Nitya Mohanty, Marike Louw, Mohlamatsane

335 Mokhatla, Alex Rebelo. We thank Donald Kramer, Peter Abrams, and an anonymous reviewer for their

336 constructive comments. We would like to thank staff at Welgevallen Experimental Farm for facilitating

337 the experimental work.

\section{References}

339 Alexander ME, Dick JTA, O'Connor NE, Haddaway NR, Farnsworth KD (2012) Functional responses of

340 the intertidal amphipod Echinogammarus marinus: effects of prey supply, model selection and habitat

341 complexity. Mar Ecol Prog Ser 468:191-202.

342

343 Alexander, ME, Dick, JTA, Weyl, OL, Robinson, TB, Richardson, DM (2014) Existing and emerging

344 high impact invasive species are characterized by higher functional responses than natives. Biol. Lett. 10:

34520130946.

346

347 Anderson, TL, Linares, C, Dodson, KN, Semlitsch RD (2016) Variability in functional response curves

348 among larval salamanders: Comparisons across species and size classes. Can J Zool 94: 23-30

349

350

Aljetlawi, AA, Sparrevik, E, Leonardsson, K (2004) Prey-predator size-dependent functional response:

351 derivation and rescaling to the real world. J. Anim. Ecol. 73: 239-252.

352

353 Asquith, C M, Vonesh, J R (2012) Effects of size and size structure on predation and inter-cohort

354 competition in red-eyed treefrog tadpoles. Oecologia 170: 629-639

355

356 Avila, V L, Frye, P G (1978) Feeding behavior of the African clawed frog (Xenopus laevis

357 Daudin):(Amphibia, Anura, Pipidae): effect of prey type. J. Herp. 12: 391-396. 
359 Barr, AR (1967) Occurrence and distribution of the Culex pipiens complex. Bull World Health Organ.

360 1967; 37(2): 293-296.

361

362 Barrios-O’Neill D, Dick JTA, Emmerson MC, Ricciardi A, HJ MacIssac (2015) Predator-free space,

363 functional responses and biological invasions. Func. Ecol. 29: 377-384.

364

365 Beauchamp, DA, Whal, DH, Johnson, BM (2007) Predator-prey interactions. In Analysis and

366 interpretation of freshwater fisheries data. (Eds) CS Guy and MJ Brown. American Fisheries Society,

367 Bethesda, Maryland, pp 765-842.

368

369

Bollache, L, Dick, JT, Farnsworth, KD, Montgomery, WI (2008) Comparison of the functional responses

of invasive and native amphipods. Biol. Lett. 4:166-169.

371

372

Brooks, J L, Dodson, S I (1965) Predation, body size, and composition of plankton. Science 150: 28-35.

373

374 Brose, U, Cushing, L, Berlow, E L, Jonsson, T, Banasek-Richter, C, Bersier, L-F, Blanchard, J L, Brey, 375 T, Carpenter, S R, Blandenier, M-F C, Cohen, J E, Dawah, H A, Dell, T, Edwards, F, Harper-Smith, S, 376 Jacob, U, Knapp, R A, Ledger, M E, Memmott, J, Mintenbeck, K, Pinnegar, J K, Rall, B C, Rayner, T,

377 Ruess, L, Ulrich, W, Warren, P, Williams, R J, Woodward, G, Yodzis, P, Martinez, N D (2005) Body 378 sizes of consumers and their resources. Ecology, 86: 2545.

379

380 Carlson, B E, Langkilde, T (2014) Predation risk in tadpole populations shapes behavioural responses of 381 prey but not strength of trait-mediated indirect interactions. Oikos 123: 1519-1527. 
383 Carpenter, S R, Kitchell, JF, Hodgson, JR (1985) Cascading trophic interactions and lake productivity.

384 BioScience 35: 634-639.

385

386 Claessen, D, Van Oss, C, de Roos, AM, Persson, L, (2000) The impact of size-dependent predation on 387 population dynamics and individual life history. Ecology 83:1660-1675.

388

389 Cohen, JE, Pimm, SL, Yodzis, P, Saldana, J (1993) Body sizes of animal predators and animal prey in 390 food webs. J. Anim. Ecol. 62: 67-78.

391

392 Courant, J, Vogt, S, Marques, R, Measey, J, Secondi, J, Rebelo, R, De Villiers, A, Ihlow, F, De

393 Busschere, C, Backeljau, T, Rödder, D, Herrel, A (2017) Are invasive populations characterized by a

394 broader diet than native populations? PeerJ 5: e3250.

395

396

Cundall, D, Fernandez, E, Irish, F (2017) The suction mechanism of the pipid frog, Pipa pipa (Linnaeus,

397 1758). Journal of Morphology. DOI: 10.1002/jmor.20707

398

399

Dean, MN (2003) Suction feeding in the pipid frog, Hymenochirus boettgeri: kinematic and behavioral 400 considerations. Copeia, 2003: 879-886.

401

402

De Villiers, FA, de Kock, M, Measey, GJ, (2016) Controlling the African clawed frog Xenopus laevis to 403 conserve the Cape platanna Xenopus gilli in South Africa. Cons. Evidence, 13, 17.

404

405 De Villiers, FA, Measey, J. (2017) Overland movement in African clawed frogs (Xenopus laevis):

406 empirical dispersal data from within their native range. PeerJ 5: e4039

407 
408 Dick, JT, Gallagher, K, Avlijas, S, Clarke, H.C, Lewis, S.E, Leung, S, Minchin, D, Caffrey, J, Alexander,

409 ME, Maguire, C, Harrod, C (2013) Ecological impacts of an invasive predator explained and predicted by

410 comparative functional responses. Biol. Invasions, 15: 837-846.

411

412 Eggers, DM (1978) Limnetic feeding behavior of juvenile sockeye salmon in Lake Washington and

413 predator avoidance. Limnol. Ocenaogr. 23: 1114-1125.

414

415 Ebenman, B (1988) Competition between age classes and population dynamics. J. Theor. Biol. 131: 389-

416400.

417

418 Englund, G, Öhlund, G, Hein, C. L, Diehl, S (2011) Temperature dependence of the functional response. 419 Ecol. Lett. 14: 914-921.

420

421 Elepfandt, A, (1996) Sensory perception and the lateral line system in the clawed frog, Xenopus. In The 422 Biology of Xenopus: Symposia of the Zoological Society of London (No. 68) Eds. H.R. Kobel \& R.C.

423 Tinsley. Oxford: Clarendon Press, pp 97-120.

424

425

Elton, CS (1927) Animal Ecology. Sidgwick and Jackson, London

426

427 Eveleigh, ES, Chant, DA (1981) Experimental studies on acarine predator-prey interactions: effects of

428 predator age and feeding history on prey consumption and the functional response (Acarina:

429 Phytoseiidae). Can J. Zool. 59: 1387-1406.

430

431 Faraone, FP, Lillo, F, Giacalone, G, Valvo, ML (2008) The large invasive population of Xenopus laevis in 432 Sicily, Italy. Amphib. Reptil. 29: 405-412.

433 
434 Griffiths, D, (1980) Foraging costs and relative prey size. Am. Nat. 116: 743-752.

435

436 González-Suárez, M. , Mugabo, M. , Decencière, B. , Perret, S. , Claessen, D. and Le Galliard, J. (2011),

437 Disentangling the effects of predator body size and prey density on prey consumption in a lizard.

438 Functional Ecology, 25: 158-165.

439

440 Haddaway, NR, Wilcox, RH, Heptonstall, RE, Griffiths, HM, Mortimer, RJ, Christmas, M, Dunn, AM

441 (2012) Predatory functional response and prey choice identify predation differences between

442 native/invasive and parasitised/unparasitised crayfish. PloS One 7: p.e32229.

443

444 Hassell, MP (1978) The dynamics of arthropod predator-prey systems. Princeton University Press.

445

446 Holling, CS (1959) The components of predation as revealed by a study of small mammal predation of

447 the European pine sawfly. Can. Entomol. 91: 293-320.

448

449 Holling, CS, (1965) The functional response of predators to prey density and its role in mimicry and

450 population regulation. Mem. Entomol. Soc. Can. 97: 5-60.

451

452 Hyatt, KD (1979) Feeding Strategy. In W.S. Hoar, D.J. Randall and J.R. Brett Fish Physiology volume 8:

453 Bioenergetics and Growth pp71-119.

454

455 Jansson, M, Persson, L, De Roos, AM, Jones, RI, Tranvik, LJ (2007) Terrestrial carbon and intraspecific

456 size-variation shape lake ecosystems. Trends Ecol. Evol. 22: 316-322.

457

458 Jeschke, JM, Kopp, M, Tollrian, R (2002) Predator functional responses: discriminating between handling 459 and digesting prey. Ecol. Monogr. 72: 95-112. 
461 Juliano, SA (2001) Nonlinear curve fitting: predation and functional response curves. In: Scheiner SM, 462 Gurevitch J (eds) Design and analysis of ecological experiments. Oxford University Press, Oxford, pp 463 178-196.

464

465 Keast, A, Webb, D. (1966) Mouth and body form relative to feeding ecology in the fish fauna of a small 466 lake, Lake Opinicon, Ontario. J. Fish. Res. Board Can. 23: 1845-1874.

467

468 Laverty, C, Dick, JTA, Alexander, ME, Lucy, FE (2015) Differential ecological impacts of invader and 469 native predatory freshwater amphipods under environmental change are revealed by comparative 470 functional responses. Biol. Inv. 17: 1761-1770

471

472

Lotka, AJ (1956) Elements of mathematical biology. Second edition. Dover Publications, New York.

473

474 Luecke, C, Vanni, MJ, Magnuson, JJ, Kitchell, JF, Jacobson, PT (1990) Seasonal regulation of Daphnia 475 populations by planktivorous fish-implications for the spring clear water phase. Limnol. Oceanogr. 35: 476 1091-1100.

477

478

Lobos, GA, Measey, GJ (2002) Invasive populations of Xenopus laevis (Daudin) in Chile. Herpetol. J. 12: 479 163-168.

480

481 Márquez, R, Esteban, M, Castanet, J (1997) Sexual size dimorphism and age in the midwife toads Alytes 482 obstetricans and A. cisternasii. J. Herp. 52-59.

483

484 McCoy, MW, Bolker, BB, Warkentin, KM, Vonesh, JR (2011) Predicting predation through prey 485 ontogeny using size-dependent functional response models. Am. Nat. 177 (6): 752-766. 
487 Measey, GJ (1998) Terrestrial prey capture in Xenopus laevis. Copeia, 787-791.

488

489 Measey, GJ (2001) Growth and ageing of feral Xenopus laevis (Daudin) in South Wales, UK. J. Zool. $490 \quad 254: 547-555$.

491

492 Measey, GJ (2004) Genus Xenopus Wagler, 1827 (Family Pipidae). In: Minter, LR, Burger, M, Harrison, 493 JA, Braack, HH Bishop, PJ, Kloepfer, D (eds.) Atlas and Red Data Book of the Frogs of South Africa, 494 Lesotho and Swaziland: pp 266-267.

495

496

Measey, J. (2016) Overland movement in African clawed frogs (Xenopus laevis): a systematic review.

497 PeerJ 4: e2474.

498

499

Miller, TJ, Crowder, LB, Rice, JA, Marschall, EA (1988) Larval size and recruitment mechanisms in

500

fishes: toward a conceptual framework. Can. J. Fish. Aquat. Sci. 45: 1657-1670.

501

502

Milonas, PG, Kontodimas, DC, Martinou, AF (2011) A predator's functional response: Influence of prey 503 species and size. Biol. Control 59: 141-146.

504

505 Mittelbach, GG (1981) Foraging efficiency and body size: a study of optimal diet and habitat use by 506 bluegills. Ecology 62(5): 1370-1386.

507

508 Oaten, A, Murdoch, WW (1975) Switching, functional response, and stability in predator-prey systems.

509 Am. Nat. 299-318.

510 
511 Paine, RT (1992) Food-web analysis through field measurement of per capita interaction strength. Nature $512355: 73-75$.

513

514 Persson, L (1987) The effects of resource availability and distribution on size class interactions in perch, 515 Perca fluviatilis. Oikos 48: 148-160.

516

517 Persson, L Leonardsson, K, de Roos, AM, Gyllenberg, M, Christensen, B. (1998) Ontogenetic scaling of

518 foraging rates and the dynamics of a size-structured consumer-resource model. Theor. Popul. Biol. 54:

$519270-293$.

520

521 R Core Team (2013) R: A language and environment for statistical computing. R Foundation for 522 Statistical Computing, Vienna, Austria. ISBN 3-900051-07-0, URL http://www.R-project.org/.

523

524 Real, LA (1977) The kinetics of functional response. Am. Nat. 111: 289-300.

525

526 Ridewood, WG (1897) On the structure and development of the hyobranchial skeleton and larynx in 527 Xenopus and Pipa; with remarks on the affinities of the Aglossa. J. Linn. Soc. Lon, Zoology, 26: 53-128. 528

529 Rindone, RR, Eggleston, DB (2011) Predator-prey dynamics between recently established stone crabs 530 (Menippe spp.) and oyster prey (Crassostrea virginica). J. Exp. Mar. Biol. Ecol. 407: 216-225.

531

532 Ringeis, A, Krumscheid, B, Bishop, P J, De Vries, C, Elepfandt, A (2017) Acoustic communication and 533 reproductive behaviour in the aquatic frog Xenopus laevis (Pipidae), a field study. African Journal of 534 Herpetology 66: 122-146. 
536 Rosenzweig, ML, MacArthur, RH, (1963) Graphical representation and stability conditions of predator-

537 prey interactions. Am. Nat. 97: 209-223.

538

539 Samhouri, JF Steele, MA, Forrester, GE (2009) Inter-cohort competition drives density dependence and 540 selective mortality in a marine fish. Ecology 90: 1009-1020.

541

542 Scharf, FS, Juanes, F, Rountree, RA (2000) Predator size-prey size relationships of marine fish predators:

543 interspecific variation and effects of ontogeny and body size on trophic-niche breadth. Mar. Ecol.:

544 Progress Series 208: 229-248.

545

546 Schoener, TW (1969) Models of optimal size for solitary predators. Am. Nat. 122: 240-285.

547

548 Schoonbee, HJ, Prinsloo, JF, Nxiweni, JG (1992) Observations on the feeding habits of larvae, juvenile 549 and adult stages of the African clawed frog, Xenopus laevis, in impoundments in Transkei. Water-SA. 18: $550 \quad 227-236$.

551

552 Schröder, A, Nilsson, KA, Persson, L, Van Kooten, T, Reichstein, B (2009) Invasion success depends on 553 invader body size in a size structured mixed predation-competition community. J. Anim. Ecol. 78:11525541162.

555

556 Sih, A (1982) Foraging strategies and the avoidance of predation by an aquatic insect, Notonecta 557 Hoffmanni. Ecology 63: 786-796.

558

559 Skelly, DK (2002) Experimental venue and the estimation of interaction strength. Ecology 83(8): 20975602101. 
562 Solomon, ME (1949) The natural control of animal populations. J. Anim. Ecol. 18:1-35.

563

564 Soluk, DA (1993) Multiple predator effects: predicting combined functional response of stream fish and 565 invertebrate predators. Ecology 219-225.

566

567 Thompson, DJ (1978) Towards a realistic predator-prey model: the effect of temperature on the functional 568 response and life history of larvae of the damselfly, Ischnura elegans. J. Anim. Ecol. 757-767.

569

570 Toscano BJ, Griffen BD (2013) Predator size interacts with habitat structure to determine the allometric 571 scaling of the functional response. Oikos, 122: 454-462.

572

573 Trexler JC, McCulloch CE, Travis J (1988) How can the functional response best be determined?

574 Oecologia 76: 206-214.

575

576

Tripet, F, Perrin, N. (1994) Size-dependent predation by Dugesia lugubris (Turbellaria) on Physa acuta

577 (Gastropoda): experiments and model. Funct. Ecol. 458-463.

578

579 Tucker MA, Rogers TL. (2014) Examining predator-prey body size, trophic level and body mass across

580 marine and terrestrial mammals. Proc. Roy. Soc. B 281:20142103.

581

582 Turell, MJ (2012) Members of the Culex pipiens complex as vectors of viruses. J Am Mosq Control

583 Assoc. 28:123-6.

584

585 Vogt, S, De Villiers, FA, Ihlow, F, Rödder, D, Measey, J, (2017) Competition and feeding ecology in two 586 sympatric Xenopus species (Anura: Pipidae). PeerJ, 5, p.e3130. 
588 Volterra, V, (1928) Variations and fluctuations of the number of individuals in animal species living 589 together. J. Cons. Int. Explor. Mer, 3: 3-51.

590

591 Vonesh J, McCoy M, Altwegg R, Landi P, Measey J (2017) Functional responses can’t unify invasion 592 ecology. Biol. Invasions 19:1673-1676.

593

594 Vucic-Pestic O, Rall BC, Kalinkat G, Brose U (2010) Allometric functional response model: body masses 595 constrain interaction strengths. Journal of Animal Ecology 79: 249-256.

596

597 Walls, M, Kortelainen, I, Sarvala, J. (1990) Prey responses to fish predation in freshwater communities. 598 Ann. Zool. Fennici. 27: 183-199.

599

600

Werner, EE (1988) Size, scaling, and the evolution of complex life cycles. In: Ebenman B, Persson L.

601

(eds) Size-structured populations pp. 60-81. Springer Berlin Heidelberg.

602

603 Werner, EE (1994) Ontogenetic scaling of competitive relations: size dependent effects and responses in 604 two anuran larvae. Ecology 75:197-213.

605

606 Wilbur, HM (1988) Interactions between growing predators and growing prey. In Ebenman B, Persson L. 607 (eds) Size-structured populations pp157-172. Springer Berlin Heidelberg

608

609 Wootton, RJ, Allen, JRM, Cole, SJ (1980). Effect of body-weight and temperature on the maximum daily

610 food consumption of Gasterosteus aculeatus L. and Phoxinus phoxinus (L) - Selecting an appropriate

611 model. J. Fish Biol. 17: 695-705.

612 


\section{Table $\mathbf{1}$ (on next page)}

Parameter estimates from logistic regression analyses of proportion of prey (Culex pipiens) consumed against initial prey density for small, medium and large size classes of Xenopus laevis predators.

Values for $1^{\text {st }}$ order and $2^{\text {nd }}$ order terms are presented with $p$-values. 
1 Table 1. Parameter estimates from logistic regression analyses of proportion of prey (Culex pipiens)

2 consumed against initial prey density for small, medium and large size classes of Xenopus laevis

3 predators. Values for $1^{\text {st }}$ order and $2^{\text {nd }}$ order terms are presented with $\mathrm{p}$ values.

4

\begin{tabular}{lcccc}
\hline Size class & $\begin{array}{c}\text { Intercept } \\
(p-v a l u e)\end{array}$ & $\begin{array}{c}1^{\text {st }} \text { order } \\
(p \text {-value })\end{array}$ & $\begin{array}{c}2^{\text {nd }} \text { order } \\
(p \text {-value })\end{array}$ & $\begin{array}{c}\text { Functional } \\
\text { response type }\end{array}$ \\
\hline Small & $2.541(<0.001)$ & $-0.007(<0.001)$ & - & II \\
Medium & $-0.106(<0.05)$ & $0.0045(<0.01)$ & $-0.000006(<0.01)$ & III \\
Large & $-1.494(<0.001)$ & $0.0098(<0.001)$ & $-0.000015(<0.001)$ & III \\
\hline
\end{tabular}

5 


\section{Table 2 (on next page)}

Results of the flexible functional response model to prey consumed by size classes of Xenopus laevis.

Parameter estimates of search coefficient ( $b$ in seconds), handling time ( $h$ in seconds) and scaling coefficient $(q)$ from fitting the flexible functional response model to prey (Culex pipiens) consumed against initial density for small, medium and large size classes of Xenopus laevis. Estimates presented with standard error. 
1 Table 2. Results of the flexible functional response model to prey consumed by size classes of Xenopus

2 laevis. Parameter estimates of search coefficient ( $b$ in seconds), handling time ( $h$ in seconds) and scaling

3 coefficient $(q)$ from fitting the flexible functional response model to prey (Culex pipiens) consumed

4 against initial density for small, medium and large size classes of Xenopus laevis. Estimates presented

5 with standard error.

6

\begin{tabular}{lccc}
\hline Parameter estimate & $b$ & $h$ & $q$ \\
\hline Small & $3.526 \pm 0.202$ & $0.005 \pm 0.0001$ & Fixed at 0 \\
Medium & $0.212 \pm 0.064$ & $0.001 \pm 0.0003$ & $0.320 \pm 0.069$ \\
Large & $0.117 \pm 0.080$ & $0.004 \pm 0.0003$ & $0.738 \pm 0.109$
\end{tabular}

7

8 
Figure 1 (on next page)

Functional responses of Xenopus laevis preying on mosquito larvae.

(A) Functional responses of individual small (red), medium (blue) and large (green) size classes of Xenopus leavis in different initial densities of mosquito larvae (per 500 I). Solid lines represent model curve and shaded areas represent 95\% confidence intervals calculated by non-parametric bootstrapping. (B) Box plots and data points for each trial with small (red, open circles), medium (blue, closed circles) and large (green, closed triangles) size classes of Xenopus leavis. 


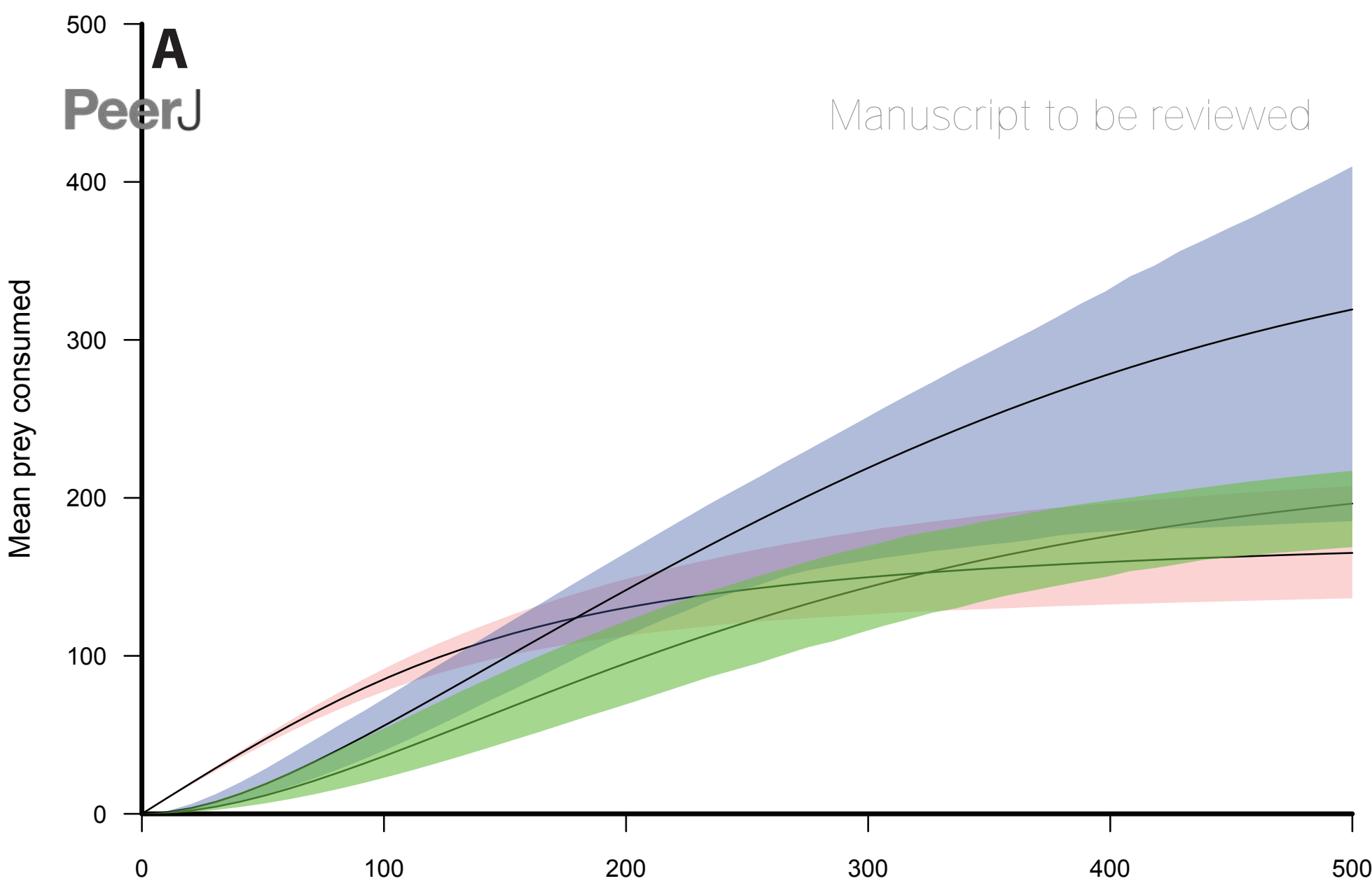

Initial prey density (mosquito larvae per 500 I)

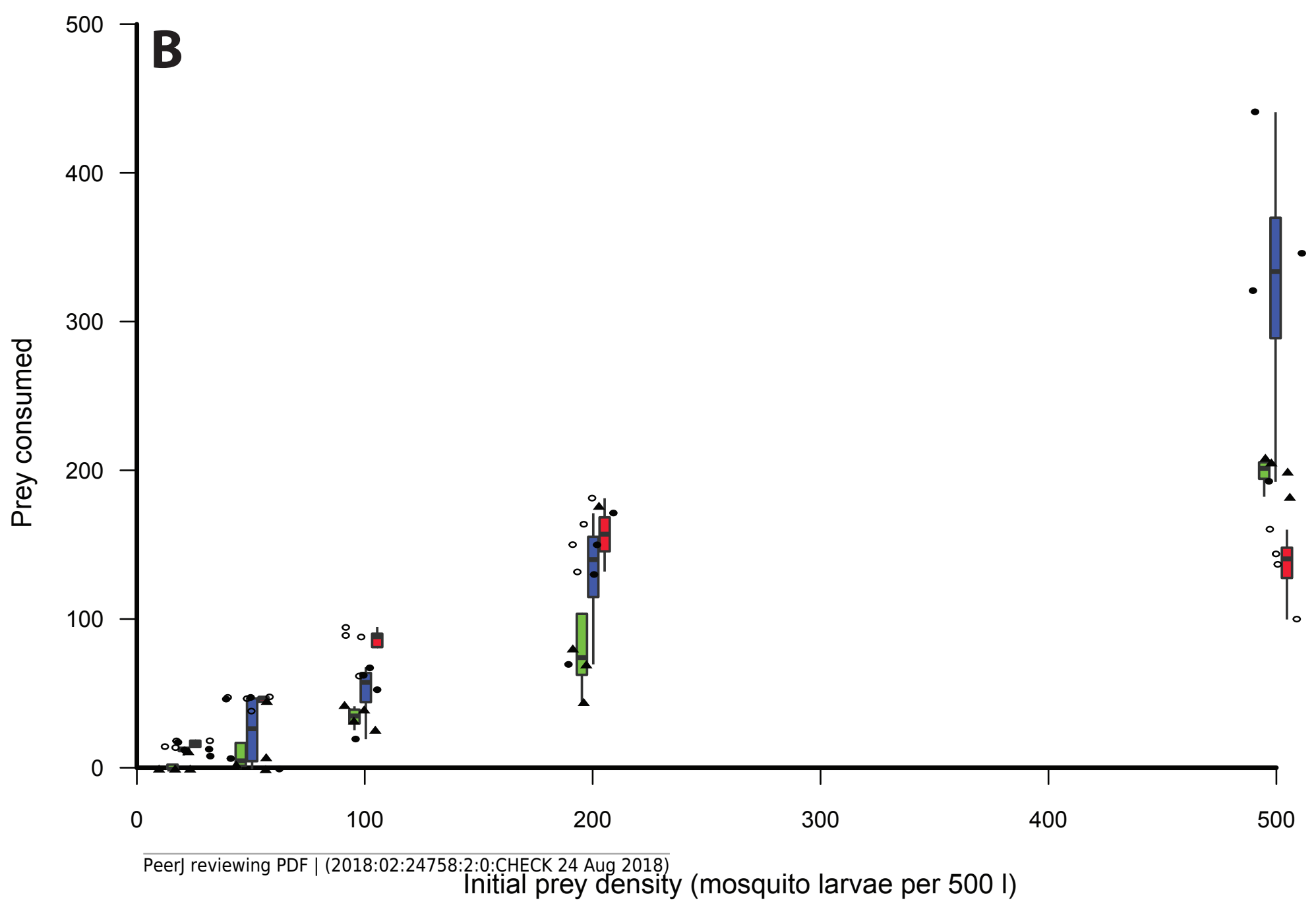


Figure 2 (on next page)

Search coefficient and handling time from functional response models.

a) Search coefficient (in seconds) and b) handling time (in seconds) parameters derived from flexible functional response models for small, medium and large size classes of Xenopus laevis. Points are original model values and error bars are bootstrapped 95\% Confidence Intervals. 


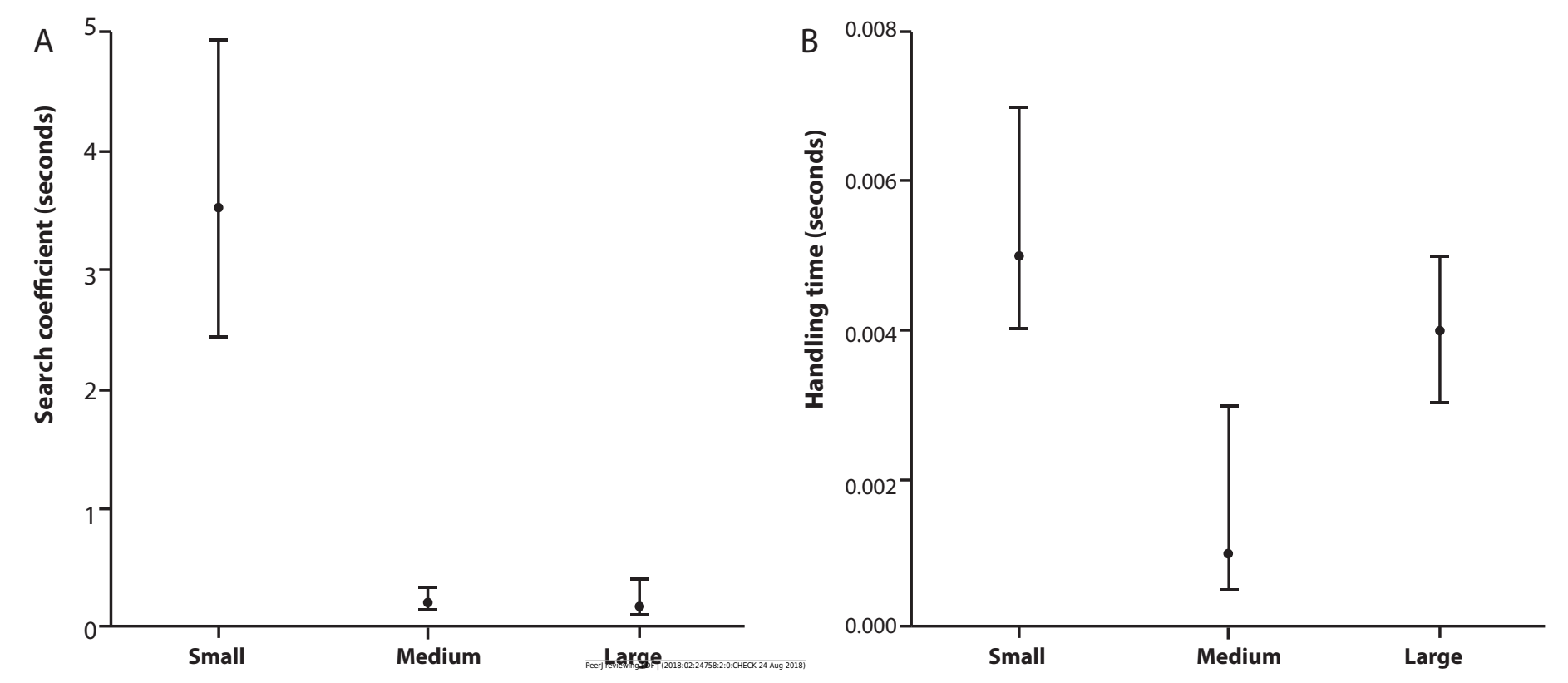

